Keywords: microRNA-183; oesophageal squamous cell carcinoma; oesophageal intraepithelial neoplasia; programmed cell death 4; tumour progression

\title{
MicroRNA-183 promotes proliferation and invasion in oesophageal squamous cell carcinoma by targeting programmed cell death 4
}

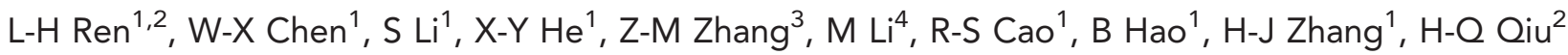 \\ and R-H Shi ${ }^{*}, 1$
}

${ }^{1}$ Department of Gastroenterology, the First Affiliated Hospital of Nanjing Medical University, Jiangsu Province, Nanjing 210029, PR China; ${ }^{2}$ Department of Gastroenterology, Zhangjiagang First People's Hospital, Affiliated Hospital of Soochow University, Jiangsu Province, Suzhou 215006, PR China; ${ }^{3}$ Department of Gastroenterology, Lianyungang First People's Hospital, Affiliated Hospital of Xuzhou Medical College, Jiangsu Province, Lianyungang 222000, PR China and ${ }^{4}$ Department of Gastroenterology, Friendliness Hospital of Yangzhou, Jiangsu Province, Yangzhou 225000, PR China

Background: Dysregulated microRNAs (miRNAs) can serve as oncogenes or suppressors and are associated with many cancers, including oesophageal squamous cell carcinoma (ESCC).

Methods: An alignment miRNA array was used to identify differentially expressed miRNAs in ESCC tissues. The expression of miR183 and programmed cell death 4 (PDCD4) in oesophageal tissues from ESCC and early oesophageal carcinoma patients was examined by quantitative reverse transcriptase PCR and western blotting. A luciferase assay was performed to confirm miR-183 target genes. The effects of miR-183 on ESCC cells and the associated mechanisms were established by in vitro experiments.

Results: We identified 51 upregulated miRNAs and 17 downregulated miRNAs in our array, and miR-183 was one of the most upregulated miRNAs. An inverse correlation between miR-183 and PDCD4 levels was found in ESCC tissues. Upregulated expression of miR-183 was not correlated with tumour stage or lymphatic metastasis in ESCC patients. The luciferase assay confirmed that miR-183 directly interacted with the PDCD4 mRNA 3'-untranslated region in ESCC cells. Overexpression of miR183 led to decreased PDCD4 protein levels and promoted ESCC cell proliferation and invasion. Inhibition of the PI3K/Akt signalling pathway increased PDCD4 protein levels and decreased miR-183 expression in ESCC cells.

Conclusions: MiR-183 promotes ESCC cell proliferation and invasion by directly targeting PDCD4, which suggests that it is involved in the pathogenesis of ESCC.

Oesophageal carcinoma (EC) is the eighth highest cause of cancer incidence and the sixth highest cause of cancer mortality worldwide (Enzinger and Mayer, 2003; Pennathur et al, 2013). Oesophageal adenocarcinoma and oesophageal squamous cell carcinoma (ESCC) show diverse aetiological and pathological characteristics (Lagergren and Lagergren, 2013). Various molecular alterations occur in precancerous lesions and are escalated in oesophageal carcinoma (EC) (Lin et al, 2013). Although multimodality therapy has improved the prognosis of patients, the overall 5-year survival rate remains unsatisfactory. Late diagnosis and tumour propensity for metastasis are believed to be associated with these poor outcomes (Pennathur et al, 2013; Takeshita et al, 2013). 
MicroRNAs (miRNAs) are a class of small non-coding RNAs that control specific gene expression by targeting messenger RNAs (mRNAs) for translational repression or by diminishing mRNA stability (Huntzinger and Izaurralde, 2011). It has been shown that miRNAs can regulate cell differentiation, proliferation, invasion, metastasis, and apoptosis (Wu et al, 2007; Sotillo and ThomasTikhonenko, 2011). Researchers have shown that specific miRNAs are aberrantly expressed in various types of malignancies, which contributes to tumour carcinogenesis and progression ( $\mathrm{He}$ et al, 2005; Lu et al, 2005), and can act as novel diagnostic biomarkers and therapeutic targets for many cancers. Using microarrays, we found that miR-183 was one of the most upregulated genes. The expression of miR-183 in various cancer types is controversial (Earle et al, 2010; Lehmann et al, 2010; Li et al, 2010; Liu et al, 2013; Ueno et al, 2013; Wang et al, 2013; Yoshino et al, 2013), and its expression and role in early EC and ESCC tissues remain undetermined.

Programmed cell death 4 (PDCD4), a tumour suppressor gene, has been implicated in cell transformation, invasiveness, and tumourigenesis. One study demonstrated a significant inverse correlation between PDCD4 expression and tumour stage, nodal metastasis, and vascular and perineural invasion in ESCC patients (Fassan et al, 2010). A recent study indicated that miR-183 could inhibit the apoptosis of TGF- $\beta 1$-induced human hepatocellular carcinoma (HCC) cells by repressing PDCD4 expression (Li et al, 2010). Nevertheless, whether miR-183 can modulate PDCD4 expression in human ESCC cells remains unknown.

Here, we report the identification of 68 aberrantly expressed miRNAs in ESCC tissues and suggest that miR-183 is a candidate oncogenic miRNA in ESCC. Our experiments showed that miR183 promoted ESCC cell proliferation and invasion by binding to the $3^{\prime}$ - untranslated region ( $3^{\prime}$-UTR) of PDCD4 mRNA, which has a fundamental role in the development and progression of ESCC.

\section{MATERIALS AND METHODS}

Patients and tissue specimens. Primary ESCC tissues, oesophageal intraepithelial neoplasia tissues, and paired normal oesophageal tissues were obtained from patients who underwent esophagectomy or endoscopic submucosal dissection without radiotherapy or chemotherapy in the Department of Cardiothoracic Surgery and Department of Gastroenterology at the First Affiliated Hospital of Nanjing Medical University from June 2012 to October 2013. With informed consent and agreement, this study was approved by the Ethics Committee of the First Affiliated Hospital of Nanjing Medical University. We obtained 32 pairs of primary ESCC, 9 pairs of oesophageal low-grade intraepithelial neoplasia (LG-IEN), 21 pairs of high-grade intraepithelial neoplasia (HG-IEN), and normal controls. All specimens were snap-frozen in liquid nitrogen within
$2 \mathrm{~h}$ and stored at $-80^{\circ} \mathrm{C}$ until they were analysed. Five pairs of primary ESCC tissues were used to make paraffin section. The grading of tumour is according to the 2010 WHO classification of tumour of the digestive system (Dixon, 2002; Montgomery et al, 2010).

ESCC cell lines. The human ESCC cell lines Eca109 and TE13 were obtained from the Shanghai Institute of Biochemistry and Cell Biology (Shanghai, China). Cells were grown in RPMI 1640 (Invitrogen, Carlsbad, CA, USA) supplemented with 10\% fetal bovine serum (Gibco, Gaithersburg, MD, USA), 100 units of penicillin/ml, and $100 \mu \mathrm{g}$ of streptomycin/ml (Invitrogen), and they were incubated at $37^{\circ} \mathrm{C}$ in a humidified chamber supplemented with $5 \% \mathrm{CO}_{2}$.

RNA isolation and quantitative real-time PCR. Total RNA was extracted from tissue samples or cultured cells using Trizol Reagent (Invitrogen) according to the manufacturer's instructions. The expression of mature miRNAs was measured by TaqMan quantitative real-time PCR (qRT-PCR) using the TaqMan miRNA assay (Applied Biosystems, Foster City, CA, USA) and normalised using the $2^{-\Delta \mathrm{CT}}$ method to U6 small nuclear RNA levels. Programmed cell death 4 mRNA was quantified by SYBR Green qRT-PCR and normalised to GAPDH levels. The primers used to amplify PDCD4 and GAPDH are shown in Table 1. Each sample was assayed in triplicate.

Western blot analysis. Anti-human PDCD4 rabbit monoclonal IgG (1 : 1000; Cell Signaling Technology, Danvers, MA, USA), antihuman Akt rabbit monoclonal IgG (1:1000; Cell Signaling Technology), and anti-human phospho-Akt (p-Akt) rabbit monoclonal IgG (1:1000; Cell Signaling Technology) were used as primary antibodies. Tissues and cellular protein extracts were prepared using RIPA buffer in the presence of a proteinase inhibitor cocktail. We separated $30-40-n g$ protein extracts by $10 \%$ SDS-PAGE and then transferred them onto polyvinylidene fluoride membranes (Millipore, Billerica, MA, USA). Protein expression was assessed using Alpha Innotech imaging software (San Leandro, CA, USA).

Immunohistochemistry. Paraffin sections were stained with antihuman PDCD4 rabbit monoclonal IgG (1:100; Cell Signaling Technology) by incubating sections overnight at $4{ }^{\circ} \mathrm{C}$. Secondary staining was performed with biotinylated anti-rabbit IgG at room temperature for $30 \mathrm{~min}$, and tertiary staining was carried out with HRP-conjugated streptavidin according to established protocols. Images were captured using a Nikon microscope imaging system (Tokyo, Japan). Staining intensity was quantified using the Imagepro Plus 6.0 software (Media Cybernetics, Inc., Silver Spring, MD, USA) and expressed as IOD/area.

miRNAs, small interfering RNAs, and transfection. The miRNAs and small interfering RNA (siRNAs) were synthesised by GenePharma (Shanghai, China). The oligonucleotide

Table 1. Primer sequences

\begin{tabular}{|c|c|c|}
\hline Name & Forward primer & Reverse primer \\
\hline PDCD4 & 5'-GTTGGCAGTATCCTTAGCATTGG-3' & 5'-TCCACATCAGTTGTGCTCATTAC-3' \\
\hline GAPDH & 5'-CGGAGTCAACGGATTTGGTCGTAT-3' & 5'-AGCCTTCTCCATGGTGGTGAAGAC-3' \\
\hline NC & 5'-UUCUCCGAACGUGUCACGUTT-3' & 5'-UUCUCCGAACGUGUCACGUTT-3' \\
\hline miR-183 mimics & 5'-UAUGGCACUGGUAGAAUUCACU-3' & 5'-UGAAUUCUACCAGUGGCCAUAAUU-3' \\
\hline Si-PDCD4 & 5'-GUGUUGGCAGUAUCCUUAG-3' & 5'-CUAAGGAUACUGCCAACAACTT-3' \\
\hline INC & 5'-CAGUACUUUUGUGUAGUACAA-3' & 5'-UUGUACUACACAAAAGUACUG-3' \\
\hline miR-183 inhibitors & 5'-AGUGAAUUCUACCAGUGCCAUA-3' & 5'-UAUGGCACUGGUAGAAUUCACU-3' \\
\hline
\end{tabular}


sequences of the negative control (NC), hsa-miR-183 mimics, inhibitor negative control (INC), hsa-miR-183 inhibitors, and siPDCD4 (Bitomsky et al, 2008) are listed in Table 1. Transfection of plasmids and oligonucleotides was performed using Lipofectamine 2000 Reagent (Invitrogen) according to the manufacturer's protocol. After transfection, cells were used for various experiments.

Vector construction and luciferase reporter assays. The wildtype $3^{\prime}$-UTR of PDCD4 that contained predicted miR-183 target sites was amplified by PCR using the primers (forward) $5^{\prime}$-taataagctaccttttgtaagtgccatgtttattatctaatcattcca- $3^{\prime}$ and (reverse) $5^{\prime}$-ttggaatgattagataataaacatggcacttacaaaaggtagcttatt- $3^{\prime}$. To amplify mutant sequences, we used (forward) $5^{\prime}$-ttctaataagctacctttggcaggac gtttattatctaatcattcc- $3^{\prime}$ and (reverse) $5^{\prime}$-ggaatgattagataataaacgtcctgcc aaaaggtagcttattagaa- $3^{\prime}$ primers. Both mutant and wild-type $3^{\prime}$-UTR fragments were then cloned into pGL3-control vectors (Invitrogen) at $\mathrm{XbaI}$ sites. The constructed vectors were named pGLPDCD4-wt-mRNA and pGL-PDCD4-mut-mRNA. For the reporter assays, cells were transfected in 24-well plates with either miR-183 mimics or NC using Lipofectamine 2000
(Invitrogen). An identical amount of Renilla expression vector PRL-TK was co-transfected into every group to serve as a normalisation control. Reporter assays were performed at $24 \mathrm{~h}$ post-transfection using a luciferase assay kit (Promega, Madison, WI, USA).

Cell proliferation and colony formation assays. Cells transfected with RNA oligonucleotides for $24 \mathrm{~h}$ were seeded in 96 -well plates at a concentration of 3000 cells per well, and cell proliferation was measured using a Cell Counting Kit-8 (Beyotime, Haimen, China) at $24,48,72$, and $96 \mathrm{~h}$. We performed four independent replicate experiments with triplicate technical replicates in each experiment. A colony formation assay was performed by seeding 300 cells in a six-well plate. After 2 weeks, the plates were washed with phosphate-buffered saline (PBS) and fixed with methanol for $15 \mathrm{~min}$ before being stained with crystal violet at room temperature for $30 \mathrm{~min}$. Colonies ( $>50$ cells per colony) were counted after crystal violet staining.

Tumour cell migration and invasion assay. We seeded $1 \times 10^{5}$ cells per well in the top chamber of a 24 -well Transwell micropore

Table 2. Differentially expressed miRNAs selected from the miRNA array data analysis

\begin{tabular}{|l|l|l|}
\hline Upregulated miRNAs & Fold change & P-value \\
\hline miR-18a & 6.44 & 0.001959 \\
miR-223 & 6.31 & 0.003113 \\
miR-455-5p & 5.12 & 0.000183 \\
miR-455-3p & 4.87 & 0.012916 \\
miR-301a & 4.56 & 0.000865 \\
miR-183 & 4.24 & 0.026973 \\
miR-21 & 3.93 & 0.005335 \\
miR-98 & 3.15 & 0.045924 \\
miR-155 & 2.96 & 0.007045 \\
miR-3663-3p & 2.75 & 0.019775 \\
miR-454 & 2.7 & 0.022823 \\
miR-17 & 2.67 & 0.013992 \\
miR-188-5p & 2.6 & 0.021431 \\
miR-3648 & 2.57 & 0.007171 \\
miR-192 & 2.5 & 0.017703 \\
miR-185 & 2.35 & 0.009586 \\
miR-128 & 2.32 & 0.004325 \\
miR-4306 & 2.31 & 0.007383 \\
miR-20b & 2.27 & 0.025342 \\
miR-106b & 2.18 & 0.036481 \\
miR-4327 & 2.05 & 0.04616 \\
miR-429 & 2.01 & 0.030885 \\
\hline Downregulated miRNAs & \multicolumn{2}{|l}{} \\
\hline miR-133b & 17.95 & 0.00581 \\
miR-145 & 10.72 & 0.006119 \\
miR-1 & 9.55 & 0.041824 \\
miR-143 & 6.89 & 0.01257 \\
miR-145* & 5.21 & 0.016405 \\
miR-30a* & 4.02 & 0.037402 \\
miR-99a & 4.01 & 0.008188 \\
miR-497 & 3.34 & 0.003157 \\
miR-125b & 2.86 & 0.018659 \\
miR-100 & 0.01219 \\
miR-195 & miR-29c & 0.019266 \\
ma &
\end{tabular}

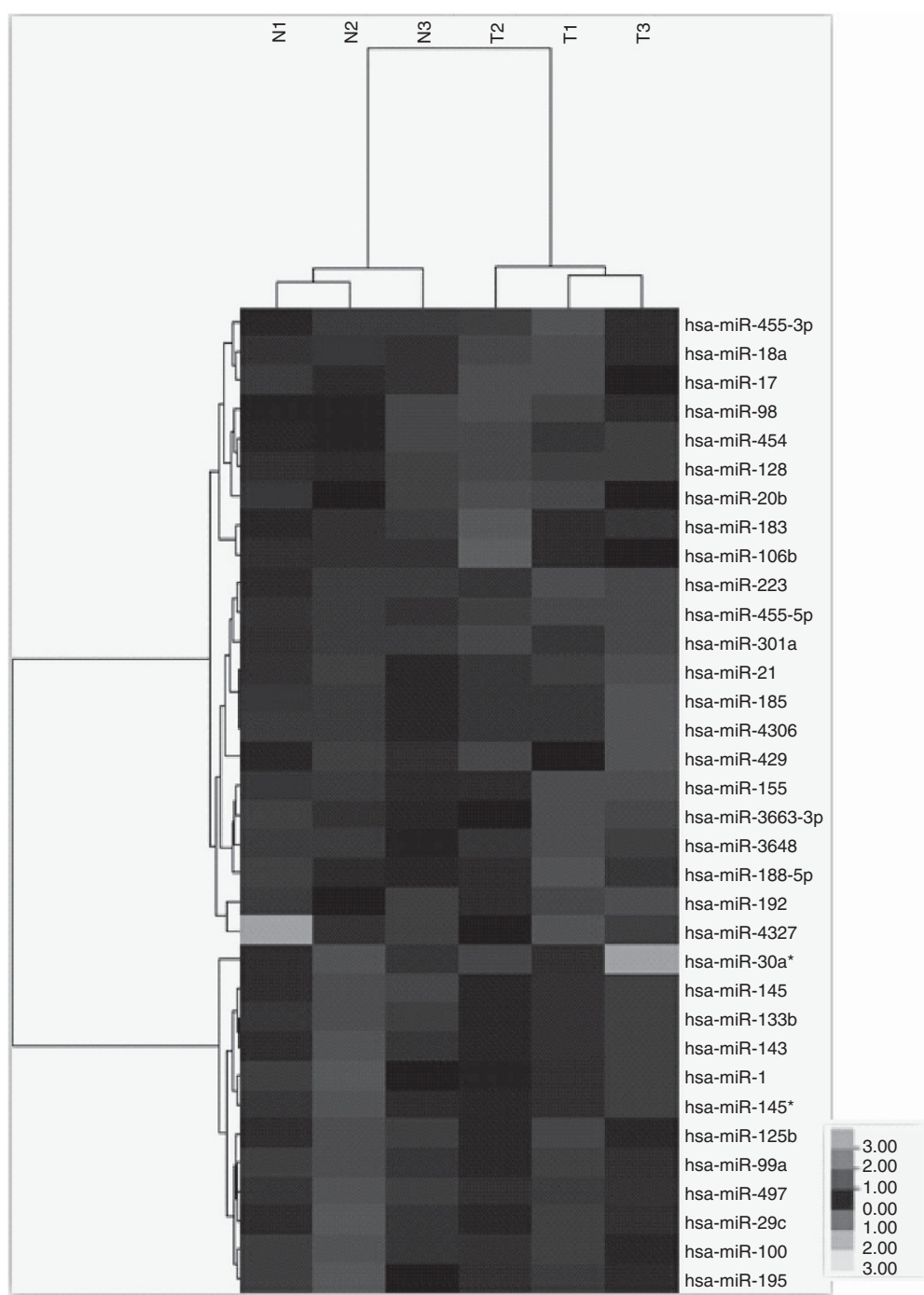

Yellow colour represents upregulated miRNAs and blue colour represents downregulated miRNAs. * is represent for the low expression level of miRNAs. The full color version of this table is available at British Journal of Cancer online. 

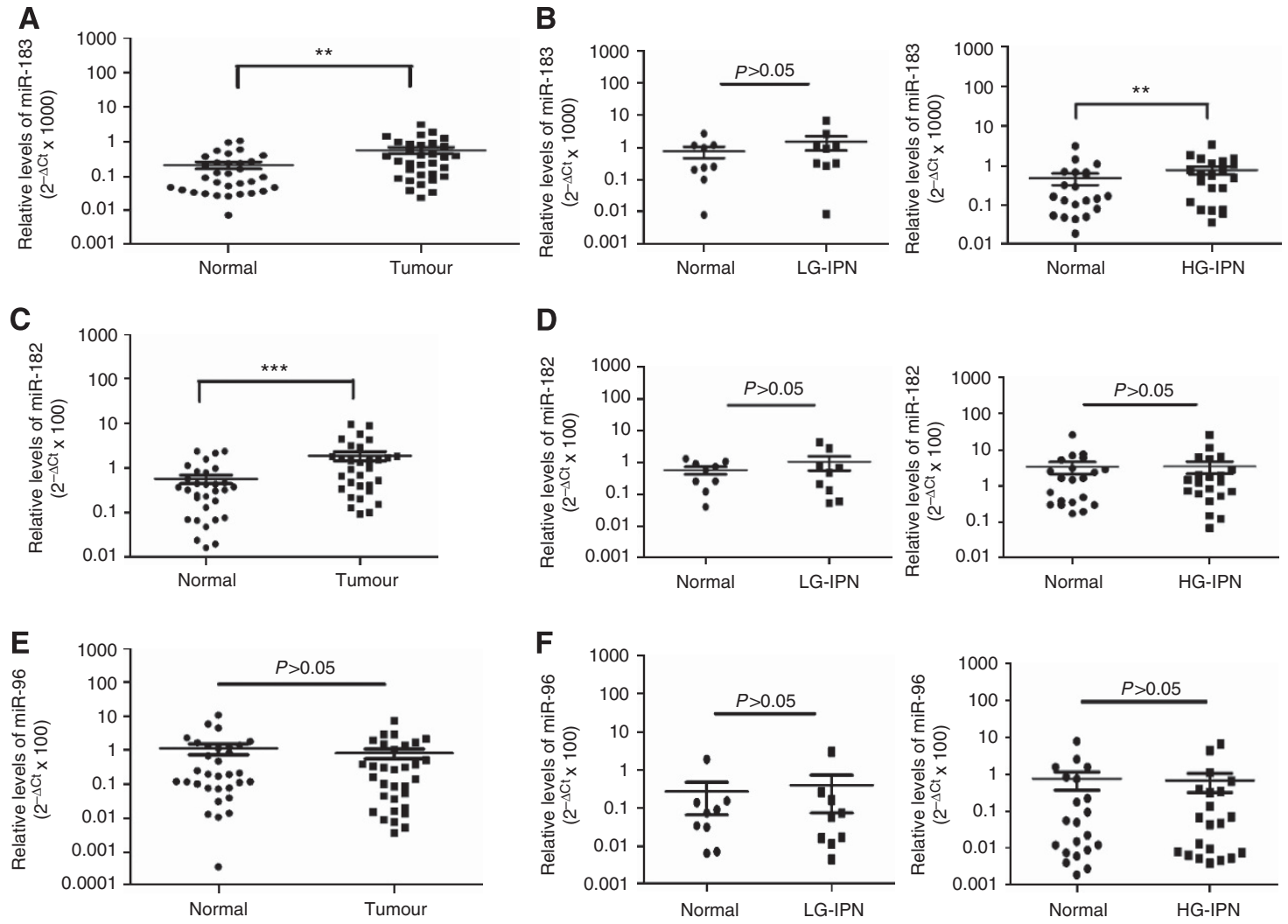

Figure 1. Analysis of miR-183 cluster levels in specimens. (A) qRT-PCR data showing miR-183 levels in oesophageal squamous cell carcinoma (ESCC) tissues and adjacent normal oesophageal tissues: T, ESCC tissues; N, normal oesophageal tissues; $n=32, * \star P<0.005$. (B) miR-183 expression in oesophageal intraepithelial neoplasia tissues and adjacent normal oesophageal tissues; LG-IEN, low-grade intraepithelial neoplasia tissues; HG-IEN, high-grade intraepithelial neoplasia tissues; $n 1=9, P>0.05 ; n 2=21,{ }^{\star} P<0.005$. (C) miR-182 expression in ESCC tissues and adjacent normal oesophageal tissues; $n=32, \star \star \star P<0.001$. (D) miR-182 expression in oesophageal intraepithelial neoplasia tissues and adjacent normal oesophageal tissues; $n 1=9, P>0.05 ; n 2=21, P>0.05$. (E) miR-96 expression in ESCC tissues and adjacent normal oesophageal tissues; $n=32, P>0.05$. (F) miR-96 expression in esophageal intraepithelial neoplasia tissues and adjacent normal oesophageal tissues; $n 1=9, P>0.05$; $\mathrm{n} 2=21, P>0.05$. The terms $\Delta \mathrm{Ct}_{(\mathrm{T} / \mathrm{IEN} / \mathrm{N})}=\mathrm{Ct}_{\text {miRNA }}-\mathrm{Ct}_{\mathrm{U}}, \Delta \Delta \mathrm{Ct}=\Delta \mathrm{Ct}_{(\mathrm{T} / \mathrm{IEN})}-\Delta \mathrm{Ct}_{(\mathrm{N})}$, and $2^{-\Delta \mathrm{Ct}(\mathrm{T} / \mathrm{IEN} / \mathrm{N})}$ are used to denote the level of miRNA in $\mathrm{T} / \mathrm{IEN} / \mathrm{N}$ tissues, $2^{-\Delta \Delta \mathrm{Ct}}$ is used to denote the relative level of miRNA in T/IEN tissues compared with $\mathrm{N}$ tissues. U6 snRNA was used as an internal control.

polycarbonate membrane filter with an $8-\mu$ m pore size (Millipore, Bedford, MA, USA); cells were suspended in culture media without serum followed by respective treatments. Complete media was added to the bottom chamber. After $48 \mathrm{~h}$, cells on the top surface of the membrane were carefully removed using a cotton swab. The total number of migrated/invaded cells was manually counted in five randomly chosen fields per treatment per insert.

Flow cytometry analysis of cell apoptosis. Detection of apoptotic cells was performed using the Annexin V-FITC/PI apoptosis detection kit (KeyGEN, Nanjing, China). Cells were harvested and washed with PBS twice, incubated in a dark room with Annexin V-FITC and propidium iodide for $15 \mathrm{~min}$, and then analysed by flow cytometry.

Statistical analysis. All experiments were performed in triplicate, with values expressed as the means \pm s.e.m. Statistical significance was determined using Student's $t$-test or one-way analysis of variance with Tukey's post-hoc test. Findings were considered to be significantly different when a $P$-value $<0.05$ was obtained. All statistical analyses were performed using the SPSS 20.0 software program (SPSS Inc., Chicago, IL, USA).

\section{RESULTS}

MiR-183 is specifically upregulated in human ESCC and oesophageal intraepithelial neoplasia tissues. We found 68 aberrantly expressed miRNAs in our microarray, including 51 highly expressed miRNAs and 17 lowly expressed miRNAs (Table 2). MiR-183 was one of the most upregulated miRNAs in ESCC tissues. To further validate this result, we used TaqMan qRTPCR assays to evaluate miR-183 levels in 32 primary ESCC tissues and paired normal oesophageal tissues, and miR-183 was significantly upregulated in the ESCC tissues (Figure 1A). Furthermore, the expression level of miR-183 in HG-IEN tissues was also higher than that in paired normal controls (Figure 1B). However, we found that miR-183 expression had no significant correlation with tumour stage or lymphatic metastases in ESCC patients; the detailed clinical characteristics of patients in our study are shown in Table 3. Because miR-96, miR-182, and miR-183 are physically clustered genes, we further investigated the expression of miR-182 and miR-96 in those 62 paired samples. We found that the expression of miR-182 was also upregulated in ESCC tissues compared with normal oesophageal tissues (Figure 1C). However, the levels of miR-182 in oesophageal intraepithelial neoplasia tissues were not significantly upregulated compared with those in paired normal controls 
(Figure 1D). The relative expression levels of miR-96 showed no significant differences in 32 paired ESCC tissues or 30 paired oesophageal intraepithelial neoplasia tissues (Figure 1E and F).

PDCD4 expression is downregulated in ESCC tissues. The expressions of PDCD4 mRNA and protein were both downregulated in ESCC tissues (Figure 2A and B), which was in accordance with the results of a previous study (Fassan et al, 2010; Peter, 2010). PDCD4 protein levels were significantly reduced in ESCC tissues compared with adjacent noncancerous tissues based on immunohistochemistry. As shown in Figure 2C, strong nuclear and cytoplasmic PDCD4 protein staining was observed in normal oesophageal epithelial tissue. However, loss of nuclear staining was observed in ESCC tissue (Figure 2C).

MiR-183 directly downregulates PDCD4 expression in ESCC cells. We searched for target genes of miR-183 in the TargetScan and miRanda databases and identified PDCD4 as a candidate miR-183 target gene (Figure 3A), and the sequence analysis indicated that miR-183 target sequence at 260-266 nt of PDCD4 3 '-UTR was highly conserved across different species (Figure $3 \mathrm{~B}$ ). To rationalise the inverse relationship between miR-183 and PDCD4 expression, we hypothesised that the increased miR-183 acted to attenuate the transcript level or translation of the tumour suppressor PDCD4 in ESCC.

To further validate the interaction of miR-183 with PDCD4, we transfected Eca109 and TE13 cells with miR-183 mimics and confirmed the reduction of PCCD4 protein expression. Furthermore, we treated ESCC cells with miR-183 inhibitors, which resulted in increased PDCD4 protein levels compared with those in scrambled control-treated cells (Figure 3C and D). However, PDCD4 mRNA levels showed no significant change during these treatments (Figure 3E).

To confirm whether PDCD4 is a bona fide target gene of miR-183, a human PDCD4 wild-type 3 '-UTR that contained either miR-183 binding sites or mutant sites was cloned into a modified pGL3-control vector. These luciferase reporter constructs were co-transfected into Eca109 and TE13 cells with miR183 mimics or NC RNAs. We observed significantly decreased luciferase activity in the cells transfected by the PDCD4-wt3 -UTR vector with miR-183 mimics compared with that in the cells transfected with control RNAs. In contrast, when the miR-183 binding site was mutated, no significant change in relative luciferase activity was found (Figure 3F). This finding suggested that miR-183 can directly bind to the $3^{\prime}$-UTR of the PDCD4 gene.

MiR-183 promotes the growth and invasion of human ESCC cells. We tested the effects of miR-183 on the growth and invasion ability of human ESCC cells. The expression of miR-183 was significantly upregulated or downregulated compared with that in controls at $24 \mathrm{~h}$ after transient transfection (Figure $4 \mathrm{~A}$ ). Based on these results, ESCC cells were transfected with miR-183 mimics and NCs, and cell proliferation was analysed by a CCK- 8 assay (Beyotime, Beijing, China) every $24 \mathrm{~h}$ for 4 days. Eca109 and TE13 cells showed significantly increased proliferation when miR-183 was overexpressed compared with the proliferation of scrambled control cells (Figure 4B). However, loss-of-function experiments showed contradictory results. Colony formation assays showed a trend similar to that revealed by the CCK- 8 assay, with cell lines overexpressing miR-183 exhibiting stronger colony formation activity, whereas inhibition of miR-183 expression showed opposite phenotypes (Figure 4C and D). In addition, Eca109 and TE13 cells transfected with miR-183 mimics for $24 \mathrm{~h}$ showed reduced apoptosis (Figure 4E). Cell migration and invasion assay showed the mean number of cells penetrating the Transwell membrane (BD Biosciences, Bedford, MA, USA) of miR-183 mimics was significantly greater than NCs (Figure $4 \mathrm{~F}$ and $\mathrm{G}$ ).
Table 3. The correlation between miR-183 expression and clinical variables of ESCC patients

\begin{tabular}{|c|c|c|c|c|}
\hline & & \multicolumn{2}{|c|}{$\begin{array}{c}\text { miR-183 expression } \\
\left(2^{-\Delta \Delta \mathrm{Ct}}\right)\end{array}$} & \multirow[b]{2}{*}{$P$-value } \\
\hline Variables & $\begin{array}{l}\text { All cases } \\
(\%)\end{array}$ & $\begin{array}{l}\text { High } \\
\text { expression } \\
\text { (n) }\end{array}$ & $\begin{array}{l}\text { Low } \\
\text { expression } \\
\text { (n) }\end{array}$ & \\
\hline Total number & 62 & & & \\
\hline \multicolumn{5}{|l|}{ Age } \\
\hline$>60$ & 39 (62.9) & 19 & & 0.79 \\
\hline$\leqslant 60$ & $23(37.1)$ & 12 & 11 & \\
\hline
\end{tabular}

\begin{tabular}{l|l|r|r|r|}
\hline Gender \\
\hline Male & $46(74.2)$ & 22 & 7 & 0.56 \\
Female & $16(25.8)$ & 9 & 7 & \\
\hline
\end{tabular}

Degree of tumour differentiation

\begin{tabular}{|l|r|r|r|r|}
\hline Cancer & $32(51.6)$ & 20 & & 0.11 \\
HG-IEN & $21(33.9)$ & 7 & 14 & \\
LG-IEN & $9(14.5)$ & 4 & 5 & \\
\hline
\end{tabular}

Tumour location

\begin{tabular}{|l|l|l|l|l|}
\hline Upper middle & $38(61.3)$ & 20 & & 0.4 \\
Lower & $24(38.7)$ & 10 & 14 & \\
\hline
\end{tabular}

Tumour size

\begin{tabular}{|c|c|c|c|c|}
\hline$>3 \times 3 \times 3 \mathrm{~cm}$ & $6(9.7)$ & 4 & & 0.06 \\
$\leqslant 3 \times 3 \times 3 \mathrm{~cm}$ & $56(90.3)$ & 16 & 40 & \\
\hline
\end{tabular}

\section{TNM stage}

\begin{tabular}{|l|l|r|l|l|}
\hline I/II & $48(77.4)$ & 21 & & 0.59 \\
III/IV & $14(22.6)$ & 5 & 9 & \\
\hline
\end{tabular}

Tumour stage

\begin{tabular}{|c|c|r|r|l}
\hline T0 & $30(48.4)$ & 11 & & 0.08 \\
T1 & $7(11.3)$ & 6 & 1 & \\
T2 & $4(6.5)$ & 1 & 3 & \\
T3 & $20(32.3)$ & 12 & 8 & \\
T4 & $1(1.5)$ & 1 & 0 & \\
\hline
\end{tabular}

Lymphatic metastasis

\begin{tabular}{|l|l|r|r|l|}
\hline Positive & $11(17.7)$ & 7 & & 0.11 \\
Negative & $51(82.3)$ & 19 & 32 & \\
\hline
\end{tabular}

Abbreviations: HG-IEN = high-grade intraepithelial neoplasia; LG-IEN = low-grade intraepithelial neoplasia; TNM $=$ tumour, node, metastasis stage. $P$-value is calculated by $\chi^{2}$ test.

In contrast, migration and invasion cell number was reduced by anti-miR-183 transfection (Figure $4 \mathrm{~F}$ and $\mathrm{G}$ ).

MiR-183 promotes the growth and invasion of ESCC cells by negatively regulating PDCD4. Because PDCD4 is a target gene of miR-183, we investigated whether miR-183 promoted the growth and invasion of ESCC cells by negatively regulating PDCD4. We constructed an siRNA to specifically suppress PDCD4 expression. Transfection of si-PDCD4 in ESCC cells markedly reduced the expression of PDCD4 protein (Figure 3C and D). Because miR-183 promoted the growth and migration of ESCC cells, we observed that cells treated with si-PDCD4 showed increased cell proliferation and migration activities (Figure 4B-D, F, and G). According to the flow cytometry results, cells treated with si-PDCD4 showed 

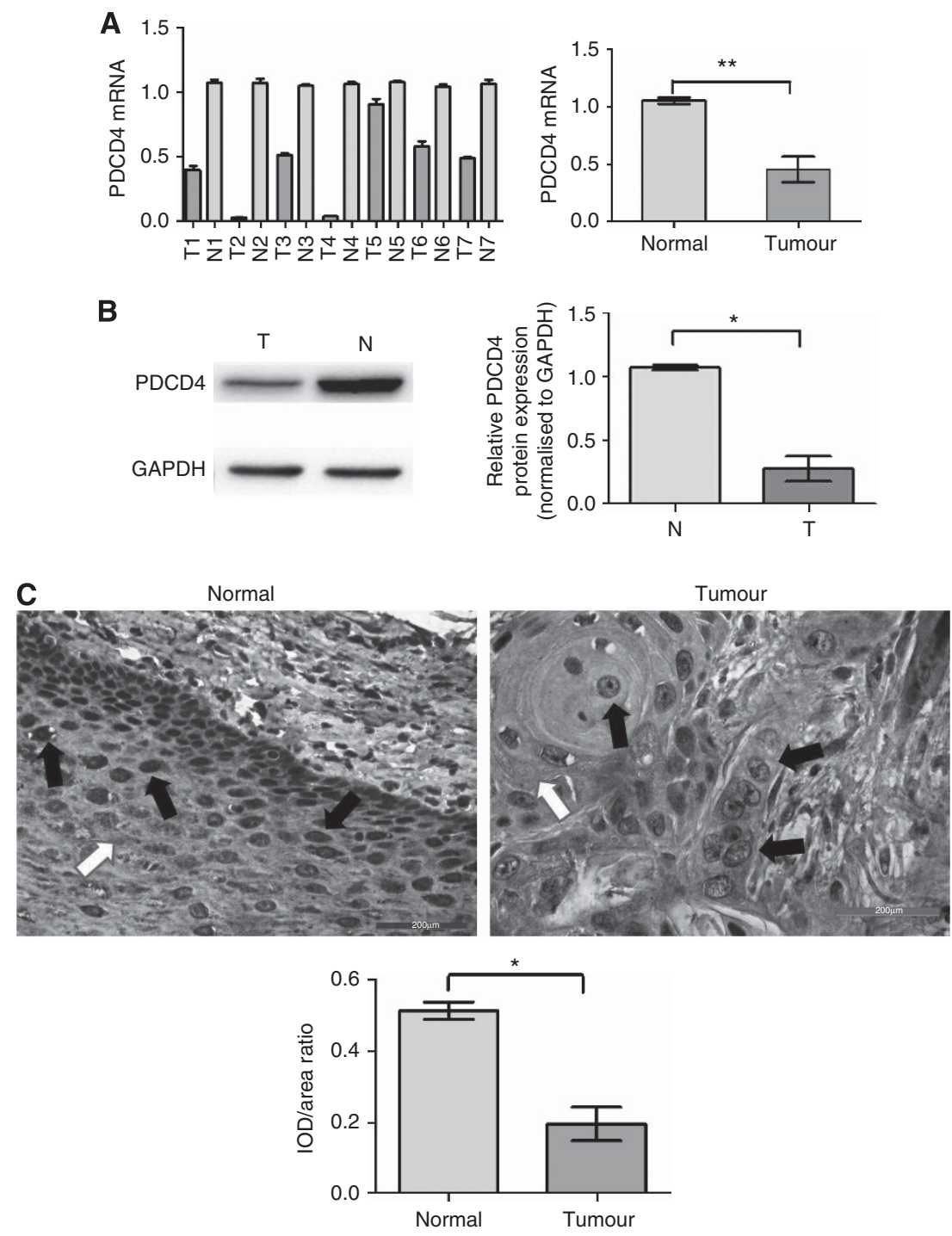

Figure 2. PDCD4 mRNA and protein expression in ESCC tissues and paired normal controls. (A) qPCR data for PDCD4 mRNA expression in seven paired primary ESCC tissues. (B) Western blotting was performed to detect PDCD4 protein expression; N, normal tissues; $T$, ESCC tissues; $n=3$. (C) Detection of PDCD4 protein expression by immunohistochemistry in ESCC tissues and paired normal controls; $n=5$. The nuclear and cytoplasmic localisation of PDCD4 was indicated with the black and white arrows. Scale bars, $200 \mu \mathrm{m}$. GAPDH was used as the internal normalised reference for PDCD4 expression levels. Error bars (s.e.m.) were calculated based on triplicate samples $\left({ }^{\star \star} P<0.005,{ }^{\star} P<0.05\right)$.

decreased apoptosis compared with mock-treated and NC cells (Figure $4 \mathrm{E}$ ). These results are similar to those obtained with the miR-183 mimics, which indicated that miR-183 induced ESCC cell proliferation, migration, and invasion ability by downregulating PDCD4 expression.

MiR-183 expression is inhibited by LY294002 in ESCC cells. LY294002, a PI3K/Akt pathway inhibitor, decreased p-Akt levels in ESCC cells, especially at $10 \mu \mathrm{m}$, but had no effect on total Akt levels (Figure 5A). However, ESCC cells treated with $10 \mu \mathrm{M} \mathrm{LY} 294002$ did show increased PDCD4 expression. Because PDCD4 is a downstream effector of the PI3K/Akt/mTOR signalling pathway, we explored whether the PI3K/Akt signalling pathway influenced the expression of miR-183 in ESCC cells. Compared with miR-183 levels in cells treated with dimethyl sulfoxide, which served as an $\mathrm{NC}$, the expression of miR-183 in ESCC cells treated with 10 or $40 \mu \mathrm{M}$ LY294002 showed an $\sim 80 \%$ or $\sim 90 \%$ reduction in miR183 levels, respectively (Figure 5B). These data suggest that inhibition of the PI3K/Akt signalling pathway may play an important role in the regulation of miR-183 expression in ESCC cells.

\section{DISCUSSION}

This study reported that the expression of miR-183 was significantly upregulated in human ESCC tissues. It also showed for the first time that miR-183 is highly expressed in oesophageal intraepithelial neoplasia tissues, which indicates that miR-183 may act as an oncogene in ESCC. Ectopic expression of miR-183 was associated with ESCC cell proliferation, migration, and invasion ability, whereas silencing of miR-183 showed the opposite effects, partly by negatively regulating PDCD4 expression. In vitro experiments indicated that PDCD4 is a direct target gene of miR-183. In addition, inhibiting PI3K/Akt signalling significantly reduced miR-183 levels and increased PDCD4 expression, indicated that Akt may act as an upstream regulator of miR-183 in ESCC. In a word, our study showed that miR-183 may play an essential role in tumourigenesis and the progression of human ESCC.

MiR-183, a member of the miR-183-96-182 cluster, is located at the human 7q31-34 locus and contains highly conserved sequences (Sarver et al, 2010; Mihelich et al, 2011; Ueno et al, 2013). It has 
A

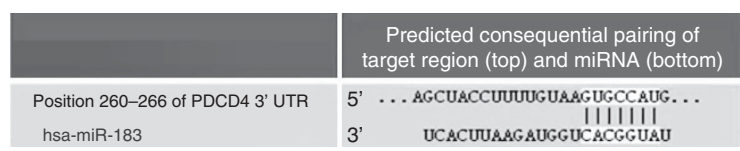

B

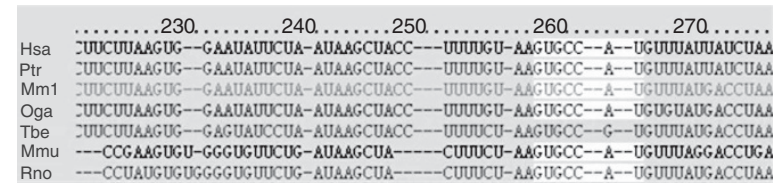

C
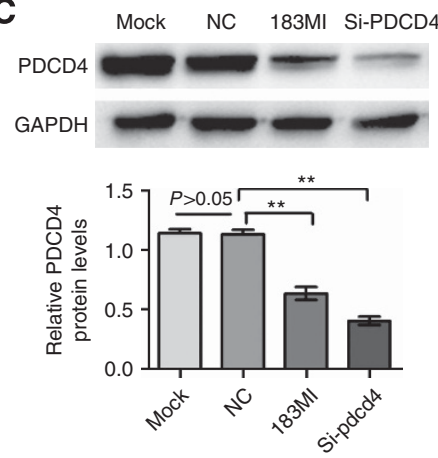

Eca109
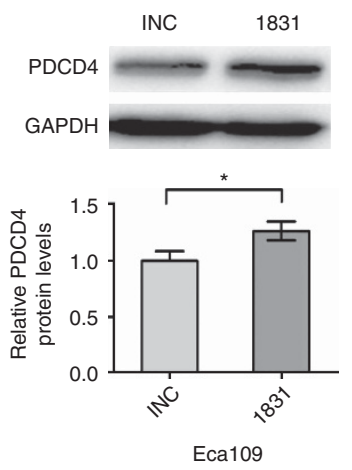

Eca109
D
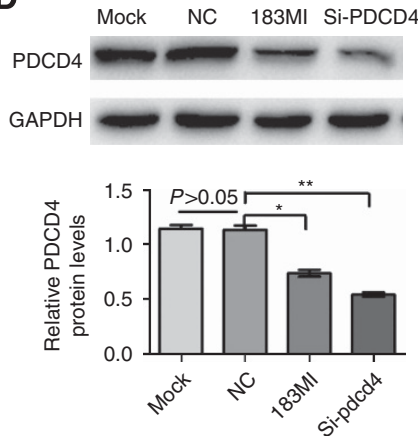

TE13
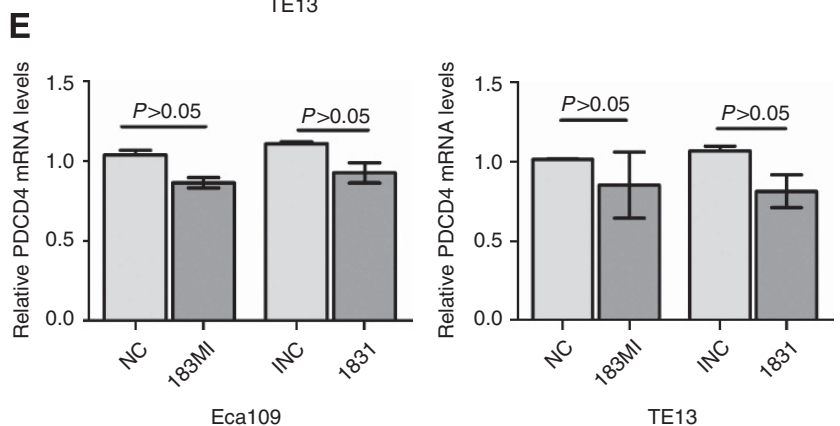

$\mathbf{F}$
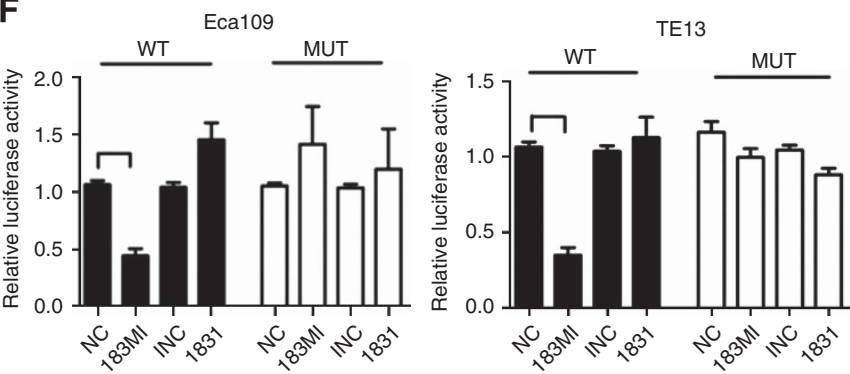

Figure 3. MiR-183 targets PDCD4 in ESCC cells. (A) Bioinformatics tools were used to predict the binding region of miR-183 in the PDCD4-3'-UTR. (B) Sequence analyses indicated the miR-183 target sequences for different species. (C) miR-183 and si-PDCD4 expression affects PDCD4 protein expression in Eca109 and TE13 cells (D) but does not affect PDCD4 mRNA expression (E) in ESCC cells. (F) Luciferase activity after transfection with wild-type (WT)/mutant-type (MUT) $3^{\prime}-$-UTR constructs in PDCD4. Error bars (s.e.m.) were calculated based on triplicate samples (**P<0.005, $\star P<0.05)$.

been found to be upregulated in multiple cancer types in humans, such as HCC (Li et al, 2010), breast cancer (Lehmann et al, 2010), colorectal cancer (Earle et al, 2010), bladder cancer (Yoshino et al, 2013), myelomonocytic leukemia (Liu et al, 2013), and prostate cancer (Ueno et al, 2013), and was therefore considered to be an oncogene. Liu et al (2012) investigated miR-183 expression in ESCC tissues and patients' blood samples and found that the relative expression of miR-183 in ESCC tissues was significantly associated with an increased risk for oesophageal cancer; however, the levels of circulating miR-183 were significantly reduced in cancer patients, suggesting that miRNAs had a source of origin distinct from tumour cells. Until recently, the mechanism underlying miR-183 regulation in ESCC had not been clearly elucidated.

The incidence of low- and high-grade oesophageal intraepithelial neoplasia, a precancerous lesion of ESCC, has increased globally. It is estimated that $\sim 20 \%$ of all oesophageal cancers are early carcinomas in Japan (Shimizu et al, 2013). Endoscopic submucosal dissection of early oesophageal cancer is a new but difficult technique that must be performed by endoscopists (Wani et al, 2013; Zhang et al, 2013). In this study, we first explored miR183 expression in oesophageal intraepithelial neoplasia tissues and found that miR-183 was upregulated in early EC tissues compared with paired normal oesophageal tissues. Because miR-182-96-183 is a physically linked gene cluster, we investigated miR-182 and -96 expression in our 62 paired tissue samples. As expected, miR-182 expression levels in ESCC tissues showed the same trend as miR183 levels, but the expression level of miR-182 in oesophageal intraepithelial neoplasia tissues was not significantly upregulated compared with that in paired normal controls. In addition, the relative expression levels of miR-96 showed no significant differences in the 62 paired tissues. Unfortunately, we found that the expression of miR-183 showed no significant correlation with tumour stage or occurrence of lymphatic metastases in ESCC patients. Nevertheless, the upregulated expression of miR-183 in oesophageal intraepithelial neoplasia tissues and EC tissues indicated that miR-183 may play an important role in ESCC development.

Because there have been no reports on the oncogenic functions of miR-183 in ESCC cells, we performed gain- and loss-of-function analyses (CCK-8, colony formation, Transwell assays, and flow cytometry) using transient transfections. We found that overexpression of miR-183 promoted growth, migration, invasion, and reduced apoptosis of ESCC cells, which suggested that miR-183 functions as an oncogene in ESCC cells. To further investigate how miR-183 may influence ESCC cell proliferation and invasion capacity, si-PDCD4 was transfected into ESCC cells. When ESCC 
cells were transfected with miR-183 mimics, PDCD4 levels were reduced, whereas the miR-183 inhibitors resulted in increased PDCD4 expression. In vitro studies tested the effect of si-PDCD4 and found it to be approximately similar to that of miR-183 mimics, which suggests that miR-183 may play an oncogenic role by negatively regulating PDCD4 expression in ESCC cells.
The PDCD4 gene was first isolated from a human glioma cDNA library as a tumour-associated gene (Cmarik et al, 1999). Accumulating evidence indicated that PDCD4 was a novel tumour suppressor gene, as loss or reduction of PDCD4 expression was detected in several cancers (Young et al, 2003; Afonja et al, 2004) and ectopic expression of PDCD4 reduced tumour formation in a
A

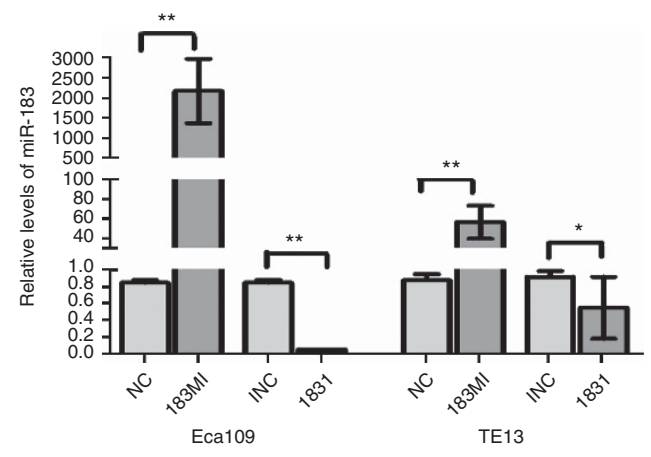

B Eca109

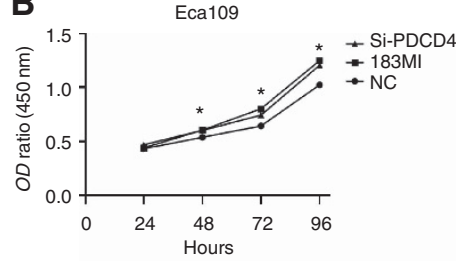

TE13

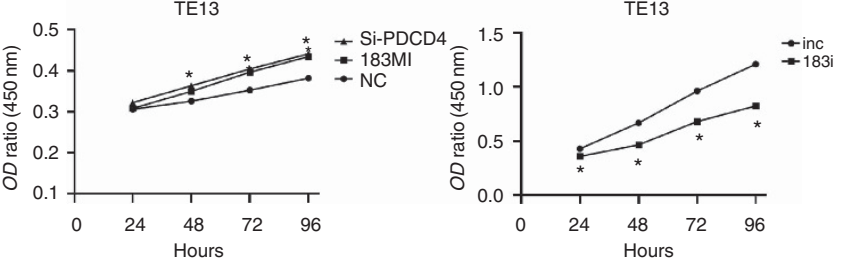

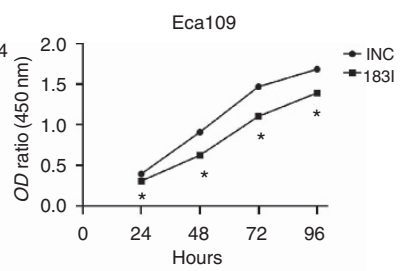

E13
C

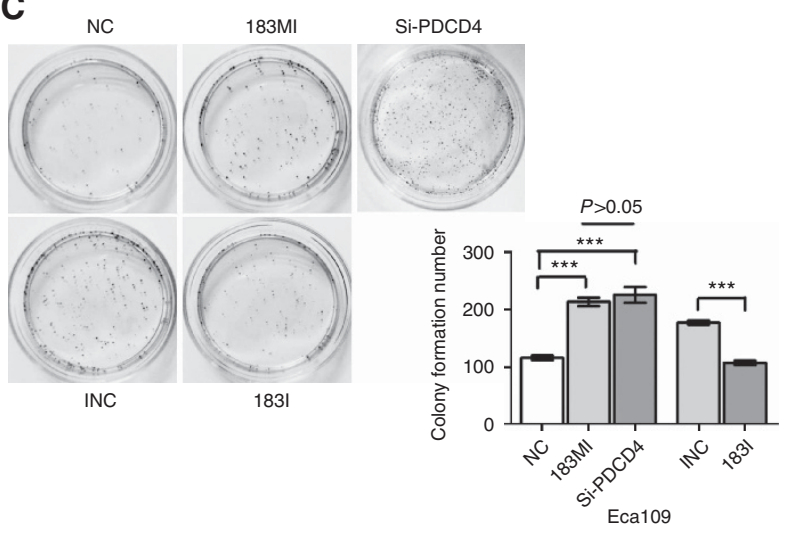

D NC

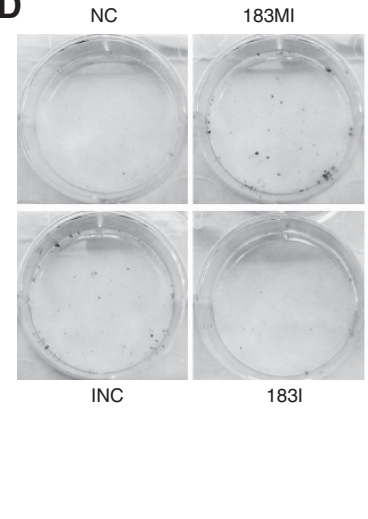

E
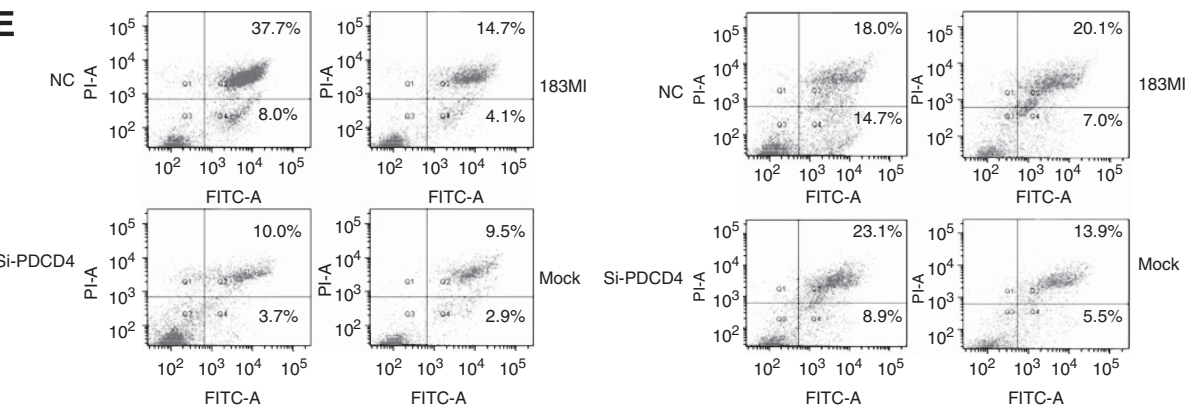

Si-PDCD4
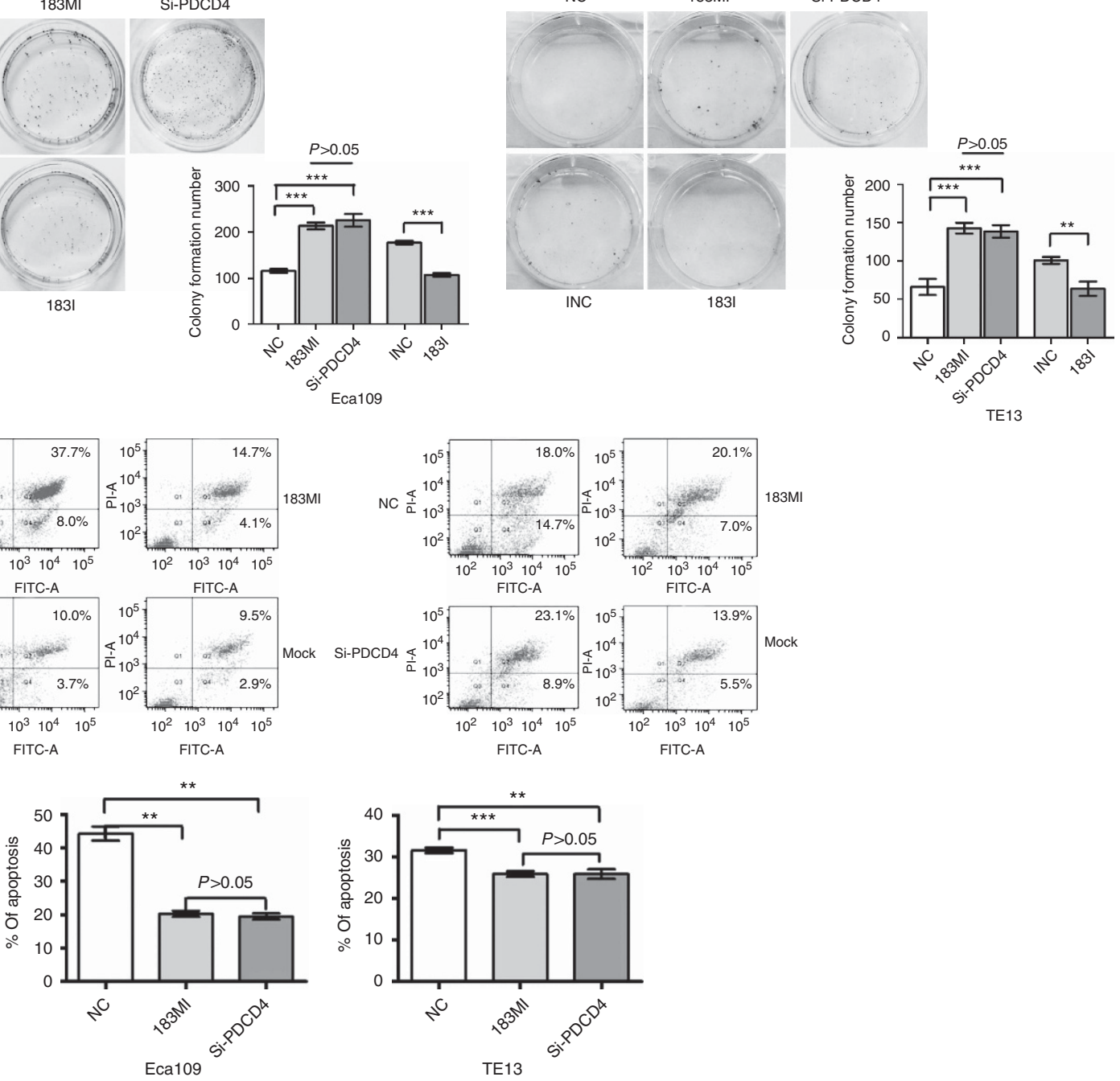

Figure 4. MiR-183 upregulation promotes ESCC cell proliferation and invasion in vitro. (A) Expression of miR-183 in ESCC cells transfected with miR-183 mimics or inhibitors by qPCR. (B) The effects of miR-183 on ESCC cell proliferation ability. (C) The effects of miR-183 on Eca109 and TE13 cell (D) colony formation ability. (E) Flow cytometry analysis of ESCC cell apoptosis after treatment with miR-183 mimics or NC after $48 \mathrm{~h}$ of transfection. The effects of miR-183 on Eca109 cell migration $(\mathbf{F})$ and invasion $(\mathbf{G})$ viability. Error bars indicate the mean \pm s.e.m. from three independent experiments ( ${ }^{\star \star \star} P<0.001,{ }^{\star \star} P<0.005$, ${ }^{\star} P<0.05$ ). 
$\mathbf{F}$

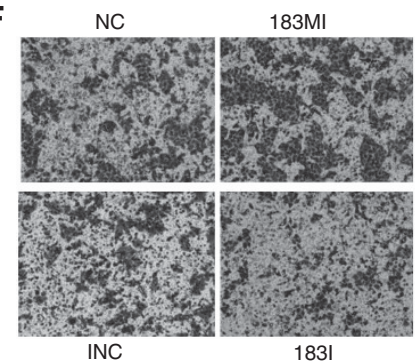

1831
G

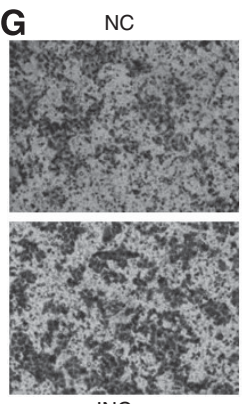

INC

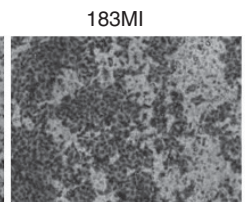

Si-PDCD4
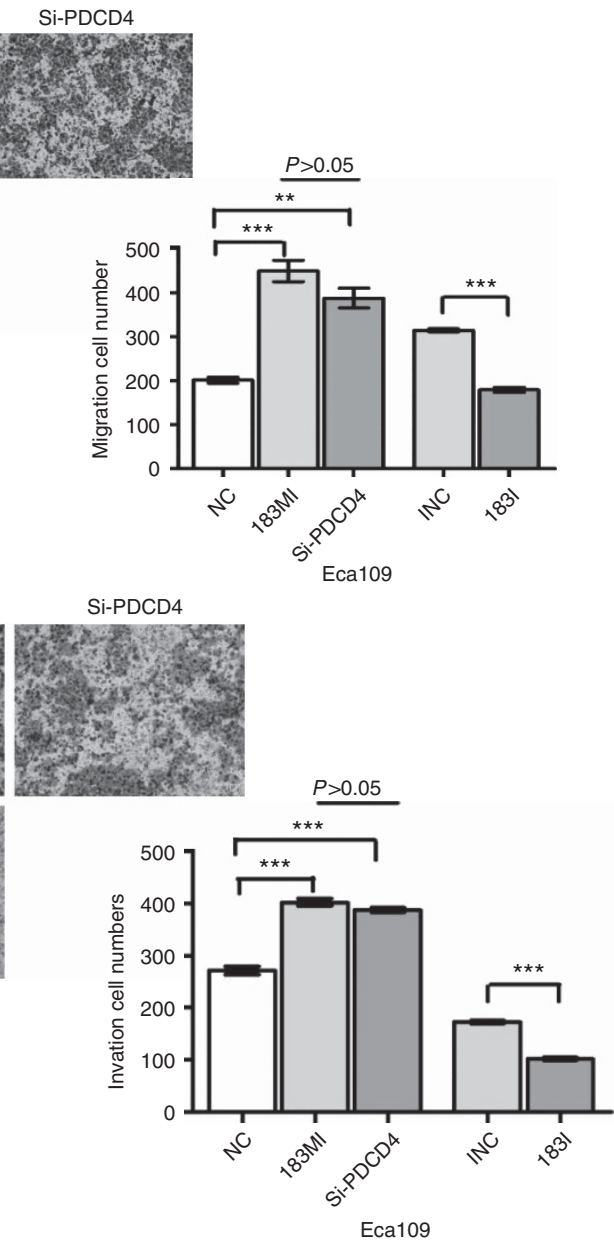

Figure 4. (continued)

mouse skin-cancer model (Jansen et al, 2005). In addition, PDCD4 can bind and inhibit translation initiation factor eukaryotic initiation factor $4 \mathrm{a}$, thereby influencing protein translation (Goke et al, 2002; Yang et al, 2003). We found that PDCD4 mRNA and protein expression was reduced in ESCC tissues, and the staining of PDCD4 was much stronger in adjacent normal oesophageal tissues compared with ESCC tissues based on immunohistochemistry, which implied that PDCD4 expression was reduced or absent in ESCC. Some previous reports have described the nuclear localisation of PDCD4 in normal tissues and the cytoplasmic localisation of PDCD4 in cancer tissues (Bohm et al, 2003; Matsuhashi et al, 2007; Mudduluru et al, 2007; Lankat-Buttgereit and Goke, 2009), whereas other studies have shown an opposite distribution (Wen et al, 2007). The reason for the diverse cellular distribution patterns of PDCD4 may be that the patterns are celltype specific (Lankat-Buttgereit et al, 2008). However, we found that the nuclear localisation of PDCD4 was reduced or lost in ESCC tissues. Studies have reported that Akt can directly phosphorylate PDCD4 at $\operatorname{Ser}^{67}$ and $\operatorname{Ser}^{457}$, which decreased transactivation of the activator protein-1 promoter by c-Jun (Palamarchuk et al, 2005). In our study, PDCD4 expression was significantly decreased by LY294002 at a dose of $10 \mu \mathrm{M}$, which suggested that the PI3K/Akt pathway was essential for regulating PDCD4 levels in ESCC cells.

Many studies have investigated the relationship between miR-21 and PDCD4, and identified PDCD4 as the target gene of miR-21 using a reporter assay (Lu et al, 2008; Reis et al, 2010). One research has shown that miR-21 overexpression in inflammatory $\mathrm{Zn}$ deficient oesophagus and tongue is correlated with PDCD4 and
TPM1 downregulation (Alder et al, 2012). It is well known that multiple miRNAs target the same gene, and it is not the one miRNA-one mRNA connection, it is the combination of multiple miRNAs that target the same gene should be considered (Peter, 2010). Studies have reported that miR-183 can inhibit TGF- $\beta 1$-induced HCC cell apoptosis by repressing PDCD4 expression (Li et al, 2010), although whether miR-183 can regulate PDCD4 expression in ESCC was not determined. Transfection of ESCC cells with a reporter plasmid containing the $3^{\prime}$-UTR of PDCD4 resulted in a significant reduction of reporter activity. In contrast, in cells transfected with plasmids containing mutant sequences of the PDCD4 3'-UTR, luciferase activity was minimally decreased in TE13 cells and the reporter activity in Eca109 cells was even increased. Therefore, miR-183 can bind to the 3'-UTR of PDCD4 mRNA in ESCC cells, inhibit PDCD4 protein expression, and promote ESCC cell growth, migration, and invasion by negatively regulating PDCD4 expression.

Previous studies have proposed that Akt is a direct regulator of miR-21 (Sayed et al, 2010). Therefore, we examined whether Akt could affect miR-183 expression. LY294002, an inhibitor of PI3K/ Akt, significantly reduced p-Akt levels in ESCC cells, without affecting total Akt levels, and increased PDCD4 levels, especially at doses of $10 \mu \mathrm{m}$. Furthermore, $\sim 80 \%$ and $\sim 90 \%$ inhibition of miR-183 expression was observed at 10 and $40 \mu \mathrm{m}$ LY294002, respectively. These results indicated that the inhibition of Akt by LY294002 contributed to the suppression of miR-183 expression. Overall, our findings suggest that inhibition of Akt phosphorylation could represent a reasonable mechanism for the downregulation of miR-183 levels and the upregulation of PDCD4 expression. 

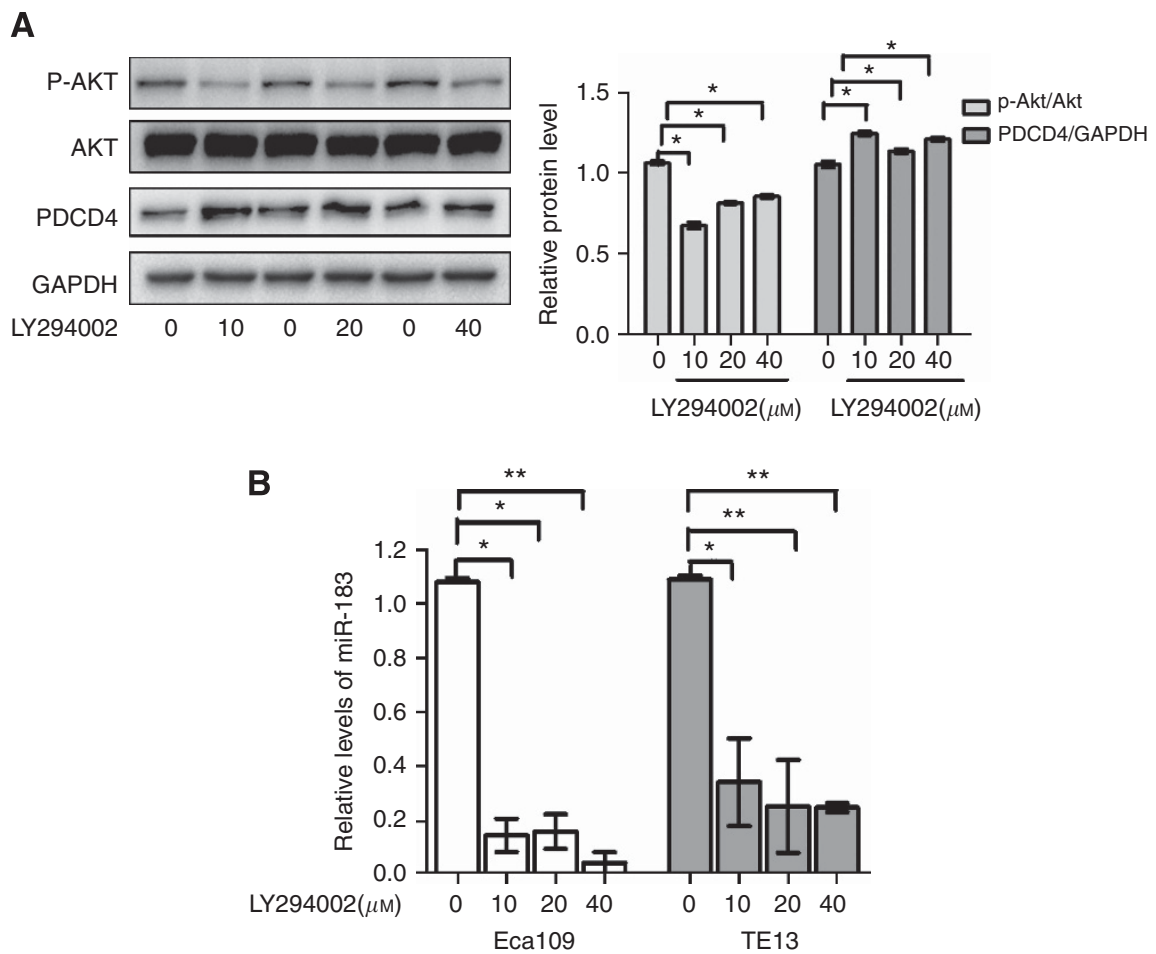

Figure 5. LY294002 inhibited the PI3K/Akt signalling pathway and reduced miR-183 expression in ESCC cells. (A) The effects of LY294002 on the $\mathrm{PI} 3 \mathrm{~K} / \mathrm{Akt}$ signal pathway and miR-183 expression in ESCC cells (B). Error bars indicate the mean \pm s.e.m. from three independent experiments $\left({ }^{\star *} P<0.005,{ }^{\star} P<0.05\right)$.

In summary, miR-183 was upregulated in ESCC and oesophageal intraepithelial neoplasia tissues compared with adjacent normal control tissues, which promoted ESCC cell proliferation, migration, and invasion ability and inhibited apoptosis by negatively regulating the tumour suppressor gene PDCD4. Inhibition of Akt phosphorylation partially reduced miR-183 levels and increased PDCD4 expression, indicating that Akt may be an upstream regulator of $\mathrm{miR}-183$.

\section{ACKNOWLEDGEMENTS}

This work was supported by grants from the Innovative Team Project, No. CX11.

\section{CONFLICT OF INTEREST}

The authors declare no conflict of interest.

\section{REFERENCES}

Afonja O, Juste D, Das S, Matsuhashi S, Samuels HH (2004) Induction of PDCD4 tumor suppressor gene expression by RAR agonists, antiestrogen and HER-2/neu antagonist in breast cancer cells. Evidence for a role in apoptosis. Oncogene 23(49): 8135-8145.

Alder H, Taccioli C, Chen H, Jiang Y, Smalley KJ, Fadda P, Ozer HG, Huebner K, Farber JL, Croce CM, Fong LY (2012) Dysregulation of miR-31 and miR-21 induced by zinc deficiency promotes esophageal cancer. Carcinogenesis 33(9): 1736-1744.

Bitomsky N, Wethkamp N, Marikkannu R, Klempnauer KH (2008) siRNA-mediated knockdown of Pdcd4 expression causes upregulation of p21(Waf1/Cip1) expression. Oncogene 27(35): 4820-4829.

Bohm M, Sawicka K, Siebrasse JP, Brehmer-Fastnacht A, Peters R, Klempnauer KH (2003) The transformation suppressor protein Pdcd4 shuttles between nucleus and cytoplasm and binds RNA. Oncogene 22(31): 4905-4910.

Cmarik JL, Min H, Hegamyer G, Zhan S, Kulesz-Martin M, Yoshinaga H, Matsuhashi S, Colburn NH (1999) Differentially expressed protein Pdcd4 inhibits tumor promoter-induced neoplastic transformation. Proc Natl Acad Sci USA 96(24): 14037-14042.

Dixon MF (2002) Gastrointestinal epithelial neoplasia: Vienna revisited. Gut 51(1): 130-131.

Earle JS, Luthra R, Romans A, Abraham R, Ensor J, Yao H, Hamilton SR (2010) Association of microRNA expression with microsatellite instability status in colorectal adenocarcinoma. J Mol Diagn 12(4): 433-440.

Enzinger PC, Mayer RJ (2003) Esophageal cancer. N Engl J Med 349(23): 2241-2252.

Fassan M, Cagol M, Pennelli G, Rizzetto C, Giacomelli L, Battaglia G, Zaninotto G, Ancona E, Ruol A, Rugge M (2010) Programmed cell death 4 protein in esophageal cancer. Oncol Rep 24(1): 135-139.

Goke A, Goke R, Knolle A, Trusheim H, Schmidt H, Wilmen A, Carmody R, Goke B, Chen YH (2002) DUG is a novel homologue of translation initiation factor $4 \mathrm{G}$ that binds eIF4A. Biochem Biophys Res Commun 297(1): 78-82.

He L, Thomson JM, Hemann MT, Hernando-Monge E, Mu D, Goodson S, Powers S, Cordon-Cardo C, Lowe SW, Hannon GJ, Hammond SM (2005) A microRNA polycistron as a potential human oncogene. Nature 435(7043): 828-833.

Huntzinger E, Izaurralde E (2011) Gene silencing by microRNAs: contributions of translational repression and mRNA decay. Nat Rev Genet 12(2): 99-110.

Jansen AP, Camalier CE, Colburn NH (2005) Epidermal expression of the translation inhibitor programmed cell death 4 suppresses tumorigenesis. Cancer Res 65(14): 6034-6041.

Lagergren J, Lagergren P (2013) Recent developments in esophageal adenocarcinoma. CA Cancer J Clin 63(4): 232-248.

Lankat-Buttgereit B, Goke R (2009) The tumour suppressor Pdcd4: recent advances in the elucidation of function and regulation. Biol Cell 101(6): 309-317.

Lankat-Buttgereit B, Lenschen B, Schmidt H, Goke R (2008) The action of Pdcd4 may be cell type specific: evidence that reduction of dUTPase levels might contribute to its tumor suppressor activity in Bon-1 cells. Apoptosis 13(1): 157-164. 
Lehmann U, Streichert T, Otto B, Albat C, Hasemeier B, Christgen H, Schipper E, Hille U, Kreipe HH, Langer F (2010) Identification of differentially expressed microRNAs in human male breast cancer. BMC Cancer 10: 109.

Li J, Fu H, Xu C, Tie Y, Xing R, Zhu J, Qin Y, Sun Z, Zheng X (2010) miR-183 inhibits TGF-beta1-induced apoptosis by downregulation of PDCD4 expression in human hepatocellular carcinoma cells. BMC Cancer 10: 354.

Lin Y, Totsuka Y, He Y, Kikuchi S, Qiao Y, Ueda J, Wei W, Inoue M, Tanaka H (2013) Epidemiology of esophageal cancer in Japan and China. J Epidemiol 23(4): 233-242.

Liu YL, Lensing SY, Yan Y, Cooper TM, Loh ML, Emanuel PD (2013) Deficiency of CREB and over expression of miR-183 in juvenile myelomonocytic leukemia. Leukemia 27(7): 1585-1588.

Liu R, Liao J, Yang M, Shi Y, Peng Y, Wang Y, Pan E, Guo W, Pu Y, Yin L (2012) Circulating miR-155 expression in plasma: a potential biomarker for early diagnosis of esophageal cancer in humans. J Toxicol Environ Health A 75(18): 1154-1162.

Lu J, Getz G, Miska EA, Alvarez-Saavedra E, Lamb J, Peck D, Sweet-Cordero A, Ebert BL, Mak RH, Ferrando AA, Downing JR, Jacks T, Horvitz HR, Golub TR (2005) MicroRNA expression profiles classify human cancers. Nature 435(7043): 834-838.

Lu Z, Liu M, Stribinskis V, Klinge CM, Ramos KS, Colburn NH, Li Y (2008) MicroRNA-21 promotes cell transformation by targeting the programmed cell death 4 gene. Oncogene 27(31): 4373-4379.

Matsuhashi S, Narisawa Y, Ozaki I, Mizuta T (2007) Expression patterns of programmed cell death 4 protein in normal human skin and some representative skin lesions. Exp Dermatol 16(3): 179-184.

Mihelich BL, Khramtsova EA, Arva N, Vaishnav A, Johnson DN, Giangreco AA, Martens-Uzunova E, Bagasra O, Kajdacsy-Balla A, Nonn L (2011) miR-183-96-182 cluster is overexpressed in prostate tissue and regulates zinc homeostasis in prostate cells. J Biol Chem 286(52): 44503-44511.

Montgomery E, Field JK, Boffetta P, Daigo Y, Shimizu M, Shimoda T (2010) Squamous cell carcinoma of the oesophagus. In: Bosman FT, Carneiro F, Hruba RH, Theise ND (eds) WHO classification of tumours of the digestive system. IARC: Lyon, pp 12-24.

Mudduluru G, Medved F, Grobholz R, Jost C, Gruber A, Leupold JH, Post S, Jansen A, Colburn NH, Allgayer H (2007) Loss of programmed cell death 4 expression marks adenoma-carcinoma transition, correlates inversely with phosphorylated protein kinase $\mathrm{B}$, and is an independent prognostic factor in resected colorectal cancer. Cancer 110(8): 1697-1707.

Palamarchuk A, Efanov A, Maximov V, Aqeilan RI, Croce CM, Pekarsky Y (2005) Akt phosphorylates and regulates Pdcd4 tumor suppressor protein. Cancer Res 65(24): 11282-11286.

Pennathur A, Gibson MK, Jobe BA, Luketich JD (2013) Oesophageal carcinoma. Lancet 381(9864): 400-412.

Peter ME (2010) Targeting of mRNAs by multiple miRNAs: the next step. Oncogene 29(15): 2161-2164.

Reis PP, Tomenson M, Cervigne NK, Machado J, Jurisica I, Pintilie M, Sukhai MA, Perez-Ordonez B, Grenman R, Gilbert RW, Gullane PJ, Irish JC, Kamel-Reid S (2010) Programmed cell death 4 loss increases tumor cell invasion and is regulated by miR-21 in oral squamous cell carcinoma. Mol Cancer 9: 238.
Sarver AL, Li L, Subramanian S (2010) MicroRNA miR-183 functions as an oncogene by targeting the transcription factor EGR1 and promoting tumor cell migration. Cancer Res 70(23): 9570-9580.

Sayed D, He M, Hong C, Gao S, Rane S, Yang Z, Abdellatif M (2010) MicroRNA-21 is a downstream effector of AKT that mediates its antiapoptotic effects via suppression of Fas ligand. J Biol Chem 285(26): 20281-20290.

Shimizu M, Zaninotto G, Nagata K, Graham DY, Lauwers GY (2013) Esophageal squamous cell carcinoma with special reference to its early stage. Best Pract Res Clin Gastroenterol 27(2): 171-186.

Sotillo E, Thomas-Tikhonenko A (2011) Shielding the messenger (RNA): microRNA-based anticancer therapies. Pharmacol Ther 131(1): 18-32.

Takeshita N, Hoshino I, Mori M, Akutsu Y, Hanari N, Yoneyama Y, Ikeda N, Isozaki Y, Maruyama T, Akanuma N, Komatsu A, Jitsukawa M, Matsubara H (2013) Serum microRNA expression profile: miR-1246 as a novel diagnostic and prognostic biomarker for oesophageal squamous cell carcinoma. Br J Cancer 108(3): 644-652.

Ueno K, Hirata H, Shahryari V, Deng G, Tanaka Y, Tabatabai ZL, Hinoda Y, Dahiya R (2013) microRNA-183 is an oncogene targeting Dkk-3 and SMAD4 in prostate cancer. Br J Cancer 108(8): 1659-1667.

Wang J, Wang X, Li Z, Liu H, Teng Y (2013) MicroRNA-183 suppresses retinoblastoma cell growth, invasion, and migration by targeting LRP6. FEBS J 281(5): 1355-1365.

Wani S, Drahos J, Cook MB, Rastogi A, Bansal A, Yen R, Sharma P, Das A (2013) Comparison of endoscopic therapies and surgical resection in patients with early esophageal cancer: a population-based study. Gastrointest Endosc 79(2): 224-232.

Wen YH, Shi X, Chiriboga L, Matsahashi S, Yee H, Afonja O (2007) Alterations in the expression of PDCD4 in ductal carcinoma of the breast. Oncol Rep 18(6): 1387-1393.

Wu W, Sun M, Zou GM, Chen J (2007) MicroRNA and cancer: current status and prospective. Int J Cancer 120(5): 953-960.

Yang HS, Jansen AP, Komar AA, Zheng X, Merrick WC, Costes S, Lockett SJ, Sonenberg N, Colburn NH (2003) The transformation suppressor Pdcd4 is a novel eukaryotic translation initiation factor $4 \mathrm{~A}$ binding protein that inhibits translation. Mol Cell Biol 23(1): 26-37.

Yoshino H, Seki N, Itesako T, Chiyomaru T, Nakagawa M, Enokida H (2013) Aberrant expression of microRNAs in bladder cancer. Nat Rev Urol 10(7): 396-404.

Young MR, Yang HS, Colburn NH (2003) Promising molecular targets for cancer prevention: AP-1, NF-kappa B and Pdcd4. Trends Mol Med 9(1): $36-41$.

Zhang YM, Boerwinkel DF, He S, Weusten BL, Xue LY, Fleischer DE, Lu N, Dawsey SM, Zuo SM, Qin XM, Dou LZ, Bergman JJ, Wang GQ (2013) Prospective feasibility study on the use of multiband mucosectomy for endoscopic resection of early squamous neoplasia in the esophagus. Endoscopy 45(3): 167-173.

This work is published under the standard license to publish agreement. After 12 months the work will become freely available and the license terms will switch to a Creative Commons AttributionNonCommercial-Share Alike 3.0 Unported License. 